\title{
A Discussion on the Application of Multimodal Theory in College English Teaching Reform
}

\author{
Fei Ma
}

Foreign Language Department, The Engineering \& Technical College of Chengdu University of Technology, Leshan City, Sichuan Province, 614000, China

\begin{abstract}
With the continuous development of information technology, the information transmission method is not limited to the single text any more. From the perspective of multimodal theory, college experiential English teaching is a new field of foreign language teaching and research, which emphasizes the construction of real contexts of language learning with various modals and forms. Based on the author's learning and practical experience, this paper first analyzed the application value of multimodal theory, and then discussed the application of multimodal theory in college English teaching reform from the reform of teaching materials, the design of teaching activities and the change of learning styles. The results of this study contribute to developing students' multi-literacy ability, English comprehensive competence and independent learning capability. Keywords: Multimodal; Teaching model; Multi-literacy ability; Independent learning
\end{abstract}

\section{Introduction}

The multimodal theory in college English teaching is being used in teaching research increasingly, and it focuses on stimulating students' learning enthusiasm and improving teaching quality by virtue of the comprehensive utilization of multimodal, which has been favored by many instructors. Multimodal theory requires teachers to use various and innovative teaching resources to create vocal and visual language situations in the teaching process and to fully mobilize 
students' visual modality, auditory modality, olfactory modality, gustatory modality and tactile modality, so that students can learn English in the context of the organic cooperation of multimodal. This will enhance students' English language communicative competence so as to achieve the best teaching result[1$2]$.

\section{The Application Value of Multimodal Theory}

English is one of the most widely used languages in the world today. Our country has set up English courses since primary school, which highlights the importance of English. However, how to effectively improve English teaching level and enhance students' English ability has perplexed many teachers. The ultimate goal of English teaching is to cultivate students' English communicative competence and comprehensive language proficiency. In language communication and comprehensive application, most of the utterance meaning is not expressed by language itself, but implied in physical characteristics, phonetic features and various external environmental conditions. The physical features mainly include gestures, expressions and movements, which are synchronized with the utterance; the phonetic features contain voice, intonation, and speech speed; the external environmental conditions refer to transmitting language meaning by virtue of various acoustic, optical and electrical devices. To achieve the purpose of language communication, this context requires organic cooperation of various modals, not just a single one.

Multimodal refers to a phenomenon where people communicate with each other by means of hearing, vision, touch and other senses, and by virtue of language, images, sounds, actions and other means and symbolic resources[3]. In the traditional teaching model, multimodal discourse theory is just an unnoticed means to assist language communicative competence teaching. Obviously, the essence of multimodal theory is not reflected. Multimodal theory advocates to achieve correct interpretation of language and improve the level of English communication with the use of cooperation, correlation and complementation of multiple modals in the teaching process. College English teaching needs to put into use of multimodal theory, construct multimedia and three-dimensional teaching model, and manifest the knowledge context in books by means of pictures and sounds to mobilize students' sense systems to work together in the learning process. This will enable students to understand the text knowledge better and enhance their language communicative competence, so that the application value of multimodal theory can be fully reflected and it will become a shinning point in college English teaching reform. 


\section{Specific Measures of the Application of Multimodal Theory in College English Teaching Reform}

\subsection{The reform of teaching materials}

\section{(1) Basic language knowledge}

Words in college English textbooks are presented in a multimodal form of audio and text. By virtue of standardized speech demonstration, students can listen, repeat, imitate, compare and practice to ensure the accuracy of voice, intonation and stress so as to clear learning obstacles in pronunciation. Difficult long sentences and knowledge points should be accompanied by relevant texts, images, videos and cartoons to make a comprehensible answer for students. This will provide students with fresh, systematic and detailed teaching content. Meanwhile, students are free to choose content based on their own English level to achieve the learning objective in language.

\section{(2) Discourse structure}

The multimodal from of discourse structure can be realized in genre characteristics and interactive forms. First of all, teachers can integrate the introduction of discourse structure in English teaching with popular newspapers, magazines, television, films, advertisement and related content in the Internet to introduce common genres and their stylistic features with the use of texts, images, videos, audios and other hypertext information forms, such as argumentation, narration, exposition and other applied styles, so that students can study in a particular context. In addition, instructors should add a variety of interactive content forms to create a communicative situation, such as dialogues, discussions, questions and answers, group debates and questionnaires[4]. In that way, students will actively discuss and explore relevant information and this will mobilize their learning enthusiasm to actively create an experiential and interactive teaching atmosphere.

\section{(3) Cultural background}

Textbooks can display the relevant cultural knowledge, social customs, values, background information and other content with utility value in communication by virtue of texts, images, cartoons, videos and other modals. This will provide students with a real and interesting language learning environment, so that students can personally see, listen to, and experience the rich and colorful world. On one hand, this will meet their curiosity and thirst for knowledge. On the other hand, they can experience, perceive and acquire knowledge[4]. The construction of real contexts can make learners realize that language learning is not dull memorization and recitation, but a tie and bridge to understand and perceive the exotic culture and colorful world, which will enhance their self-learning awareness and completely change their passive learning status. This will be conducive to developing their self-learning ability and achieving effective language learning and people-centered curriculum concept. 


\subsection{The design of teaching activities}

\section{(1) The design of experiential activities}

Teachers should focus on the creation of real situations in language learning, such as dubbing famous movies or animated films and role-playing and imitating celebrities in Britain and America; instructors can let students choose content that fits their needs, hobbies or interest to share with others, such as an audio, video or cartoon. Taking "Ways to Success" in Unit 5 in Book II of Experiencing English as an example, teachers can tell students to imitate Bill Gates or Michael Jordan's interviews before class, perform their segments in groups in the classroom and select the exemplary dialogue to explain respectively. In the performance, students can learn the language in an all-round way to exercise their oral expression and language communicative competence so as to truly experience the fun of language learning.

\section{(2) The design of practical activities}

Teachers can divide students into learning groups and each group can use the media technology to combine various modals such as sounds, images, videos and cartoons in their spare time to participate in and create English advertisement, radio plays and short films. Then, they can show their audios, videos, cartoons or live performances in the classroom. For example, when teaching "Caring for Our Earth" in Unit 1 in Book III of Experiencing English, teachers may ask students to collect a wide range of English original materials on environmental protection in groups and then compile them to produce an English advertising video about environmental protection. In the classroom, teachers can analyze the success or failure of the work with students and encourage them to share their experience to enhance their language proficiency.

\section{(3) The design of language expression activities}

In the English class, teachers can arrange lectures, group debates, poetry competitions, songs and other activities for students to develop their oral expression and language communicative ability. For instance, in the third unit "Famous Brand Names" of Book III of Experiencing English, teachers can organize a small debate about the brand effect in the classroom. In the course of the debate, teachers should properly ask questions, guide students to think and give outstanding students some rewards. These activities not only enable students to have a deeper and better understanding and mastery of the language information involved in the preparation process, but also cultivate students' positive, active and conscious language learning awareness. To this end, this will help students comprehend language cultural knowledge and enhance their confidence of the realization of language learning objectives.

\section{(4) The design of integrated activities}

Multimodal network learning resource platform can make teaching activities diversified and colorful. In the English class, students can communicate and discuss some questions with other learners, experts or scholars on the network platform with the help of audios, videos and other forms in a real-time way. This will help students understand different views and thinking ways of different people. Besides, teachers can participate in some students' dialogues or 
discussions and point out the problems for them to make corrections. This can not only enrich the teachers and students' knowledge reserves, life experiences and values, but also can mobilize their enthusiasm to participate in teaching and strengthen the practice process of language learning[5]. Therefore, students can get fun from learning English, which will change the dogmatic and rigid teaching methods.

\subsection{The change of learning styles}

\section{(1) Independent learning}

Independent learning emphasizes that learners should know what they should study and how they learn. Multimodal learning platform can provide a lot of language learning materials, such as vivid, interesting and rich images, audios, videos and cartoons. With the help of language interactive context constructed by visual and auditory images, teachers can enhance students' interest in language learning, so that they can accept and acquire knowledge[6]. This will change their learning style from "you want me to learn" to "I want to learn". Students can also exercise their listening, speaking, reading, writing and translation on the network platform according to their own interests and personal needs. They can complete the course content independently and realize the goal that I can learn it. In addition, students can record their own learning process by using audios and videos at any time to realize self-monitoring, self-testing, self-evaluation and selfsummary in order to achieve the goal that I know how to learn.

\section{(2) Cooperative learning}

The multimodal learning platform can also provide cooperative learning system. Students can communicate, interact and cooperate with each other in the learning group by virtue of texts, images, audios and videos to complete various learning tasks, share resources and support each other[7]. Teachers can also be involved in the group to find general or individual problems to give students correct answers. In addition, feedback information of students' online self-learning record, learning portfolio and learning state analysis can also help teachers to track student's learning state in the teaching process, so that they can analyze and judge the teaching effect and teaching situation to timely propose improvement measures and programs.

\section{(3) Inquiry learning}

The multimodal learning platform can provide an open learning environment, which can transform the limited teaching material into infinite learning content. By means of abundant learning resources, such as texts, sounds, cartoons, films and videos, students can gain a broad learning environment to cultivate their inquiry spirit. Besides, students can also make full use of multimodal teaching resources to study and evaluate independently, so that they can assess their learning ability, figure out problems and make improvements. 


\section{Conclusion}

In teaching, teachers should pay more attention to strengthening the relationship between the modal and teaching, coordinating the relationship between the modal and language communication, and improving students' language communicative competence. Instructors should not misuse various modals and they should use the appropriate modal at the right time to get twofold results with half the effort. One of the problems that needs to be avoided in the application of multimodal is the misuse of modals which may confuse learners. The misuse of multimodal not only fails to improve the learning efficiency, but also reduces the learning effect. Therefore, strengthening and coordinating the multimodal relation is the most important problem in college English teaching reform. Undoubtedly, multimodal theory provides a new field for the college English teaching reform. With the reform tide of teaching, using multimodal theory to integrate educational philosophy will receive unexpected results. Besides, making use of multimodal theory rationally and giving full play to its best value will contribute to college English teaching considerably.

\section{Acknowledgements}

The research work was supported by A Research on Methods and Strategies of Multimodal Teaching in College English, NO. GXSKXM-16-13.

\section{References}

[1] Zeng Lei. A Research on College English Multimodal Teaching. Journal of University of Science and Technology Beijing (Social Sciences Edition), 05, pp.9-15, 2014.

[2] Zhang Li. A Research on the Application of Multimodal Discourse Analysis Theory in College English Teaching. Education Exploration, 01, pp.52-53, 2012.

[3] Li Jian. An Analysis of Multimodal Teaching in College English. The World and Chongqing (Academic Edition), 05, pp.59-61 +69, 2012.

[4] Zhang Jingcheng, Zeng Yong. A Research on the Application of Multimedia and Multimodal in College English Teaching. Journal of Hunan Industry Polytechnic, 03, pp.87-88, 2013.

[5] Fan Ling. A Discussion on the College English Teaching Reform from the Perspective of Multimodal Theory. Education Exploration, 07, pp.71-72, 2013.

[6] Wang Qiufang. An Analysis of the College English Teaching Reform from the Perspective of Multimodal Theory. Journal of Changchun Education Institute, 24, pp.95-96,2013.

[7] Li Ming, Wang Yan. A Research on College English Multimodal Teaching. Journal of Liaoning Economic Management Cadre Institute. Journal of Liaoning Economic Vocational Technological Institute, 01, pp.114-116, 2016. 